\title{
Adult Acne: Prevalence and Portrayal in Primary Healthcare Patients, in the Greater Porto Area, Portugal
}

\author{
Acne do Adulto: Prevalência e Descrição em Utentes de \\ Cuidados de Saúde Primários da Área do Grande Porto, \\ Portugal
}

Diogo SEMEDO $\bowtie^{1}$, Filipa LADEIRO 2 , Mariana RUIVO ${ }^{3}$, Carlos d'OLIVEIRA4, Filipa de SOUSA ${ }^{5}$, Mariana GAYO ${ }^{6}$, Clara LIMA $^{7}$, Frederico MAGALHÃES ${ }^{8}$, Rui BRANDÃO ${ }^{9}$, Maria BRANCO ${ }^{10}$, Isabel da SILVA ${ }^{11}$, Joana BATISTA ${ }^{3}$, João AMADO ${ }^{12}$, António MASSA ${ }^{13}$, João NEVES-AMADO ${ }^{12}$

Acta Med Port 2016 Sep;29(9):507-513 - http://dx.doi.org/10.20344/amp.6626

\section{ABSTRACT}

Introduction: Though typically found in adolescents, acne frequently affects the adult population. In Portugal, no representative studies about acne prevalence in greater populational areas are known. This study had the following objectives: calculate acne prevalence in primary healthcare patients; its characteristics, including risk factors for onset and worsening; collect information concerning selfmedication and/or prescribed treatment.

Material and Methods: Application of a questionnaire and physical examination into a convenience sample, composed by adults from 20 - 60 years old that visited, in random days, five primary healthcare centers of the Greater Porto area.

Results: From the 1,055 evaluated adults, acne prevalence was estimated at $61.5 \%$. Only $36.8 \%$ of acne suffering adults was aware of their condition. More than half of tobacco users (62.3\%) had acne. Just $25 \%$ of acne sufferers sought treatment. The most affected areas were the malars, differing from the younger disease form.

Discussion: Acne prevalence was relatively higher than other studies. The results of this study have confirmed that acne seems to be related with increased calorie intake, tobacco smoking, whole milk and fat-reduced milk consumption, hirsutism, alopecia and seborrhea.

Conclusion: In the primary healthcare set, more than half of adults were acne sufferers. These numbers show how important primary healthcare services can be in preventing and intervening when managing acne-related risk factors and psychosocial consequences.

Keywords: Acne Vulgaris/epidemiology; Adult; Portugal; Prevalence; Primary Health Care.

\section{RESUMO}

Introdução: A acne, apesar de caraterística no adolescente, afeta frequentemente o adulto. Em Portugal, não são conhecidos estudos sobre a prevalência da acne no adulto, nomeadamente observada nos grandes centros populacionais. Os objetivos deste estudo foram estimar a prevalência da acne nos utentes dos serviços de cuidados de saúde primários, as suas características, incluindo fatores de risco para início e/ou agravamento, além de coletar informação relacionada com a automedicação e/ou tratamento prescrito. Material e Métodos: Aplicação de questionário e exame físico a amostra composta por adultos entre os 20 - 60 anos de idade que visitaram, em dias aleatórios, cinco centros de saúde da área do Grande Porto.

Resultados: Dos 1055 adultos avaliados, a prevalência estimada de acne foi de 61,5\%. Apenas 36,8\% dos portadores estavam cientes da sua condição e somente $25 \%$ afirmou ter procurado tratamento. Mais de metade dos fumadores $(62,3 \%)$ apresentavam acne. A zona mais afetada foi a região malar, diferindo da forma adolescente da doença.

Discussão: A prevalência encontrada de acne foi mais elevada do que em outros estudos. A acne aparentou estar relacionada com a ingestão calórica aumentada, tabagismo, consumo de leite gordo ou meio gordo, hirsutismo, alopécia e seborreia.

Conclusão: No contexto dos cuidados de saúde primários, mais de metade dos adultos eram portadores de acne. Estes números demonstram o quão importante pode ser a prevenção e intervenção pelos profissionais dos cuidados de saúde primários, tanto para a redução de eventuais factores de risco como para a intervenção terapêutica e consequências psicossociais relacionadas com a acne. Palavras-chave: Acne Vulgaris/epidemiologia; Adulto; Cuidados de Saúde Primários; Portugal; Prevalência.

\footnotetext{
1. Centro Hospitalar de Entre o Douro e Vouga. Santa Maria da Feira. Portugal.

2. Unidade de Cuidados de Saúde Personalizados de Tarouca. Tarouca. Portugal.

3. Instituto de Ciências Biomédicas Abel Salazar. Porto. Portugal.

4. Serviço de Radiologia. Universitätsklinikum. Magdeburg. Alemanha.

5. Serviço de Oftalmologia. Hospital de Santa Maria. Centro Hospitalar Lisboa Norte. Lisboa. Portugal.

6. Unidade de Saúde Familiar das Conchas. Agrupamentos de Centros de Saúde Lisboa Norte. Lisboa. Portugal.

7. Serviço de Anestesiologia. Hospital do Divino Espírito Santo. Ponta Delgada. Açores. Portugal.

8. Serviço de Psiquiatria. West Midlands Deanery. Birmingham. Reino Unido.

9. Serviço de Saúde Pública. Hospital Vila Maria. São Paulo. Brasil.

10. Hospital de Vila Franca de Xira. Vila Franca de Xira. Portugal.

11. Serviço de Infecciologia. Centro Hospitalar do Porto. Porto. Portugal.

12. Centro de Investigação Interdisciplinar em Saúde. Universidade Católica do Porto. Porto. Portugal.

13. Clínica Dermatológica Dr. António Massa. Porto. Portugal.

$\square$ Autor correspondente: Diogo Semedo. diogo.semedo@gmail.com

Recebido: 20 de maio de 2015 - Aceite: 27 de dezembro de 2015 | Copyright @ Ordem dos Médicos 2016
} 


\section{INTRODUCTION}

Acne commonly affects adolescents and youngsters worldwide. In Portugal, acne prevalence is greater than $80 \%$ (patients aged 12 - 24 years). However, adults are frequently affected by this condition. ${ }^{1-3}$ This skin disease is estimated to affect $94 \%$ of the global population at one time, making it the eighth most prevalent disease worldwide. ${ }^{4}$

Adult acne is either acne that started in adolescence and continued into adulthood or late-onset acne (appearing after 20 or even 50 years of age). ${ }^{2}$ Although study methods were not identical (namely concerning age ranges), estimated acne prevalence in studies already exceeded $40 \%,{ }^{5}$ particularly in relatively recent studies, ${ }^{2}$ reflecting an increasing trend in the number of patients affected by this condition. . $^{2,4}$

Acne lesions and scars may cause psychological and emotional distress (depression and anxiety) comparable to those caused by chronic diseases such as diabetes, asthma, arthritis and epilepsy, both in adolescents and adults. $^{2}$

\section{MATERIAL AND METHODS}

Data collected at five health centers in the Greater Porto concerned a convenience sample of patients aged $20-60$ years who randomly visited these health centers for reasons other than skin conditions. The patient sample $(n=1,055)$ was selected from a total population of 85,855 subjects, on a proportional basis, considering the number of patients registered in each healthcare center (quota sampling).

The protocol was approved by the Ethics Committee of the Regional Health Authority; written informed consent was obtained from each participant.

Data was collected by $4^{\text {th }}$ year medical students from Abel Salazar's Institute for Biomedical Sciences, using questionnaires answered by health center patients, from January through April to exclude the modifying effects of UV light. The students involved received intensive prior training (theoretical and practical) concerning specific topics related to acne; training sessions were organized and provided by the study's dermatologist.

Acne was graded according to the Pillsbury scale. ${ }^{6}$

The (confidential) questionnaire was divided into two sections. The first part was filled by the patients themselves and contained questions regarding biographic data, dietary habits, present or past acne treatments, seasonal variation, acne location, facial hygiene-related questions and familial data regarding acne. The second part, which consisted of specific questions and an objective examination of the skin on the face and neck, was performed by observers in a private office, whose results were accurately recorded. A small pilot study was conducted beforehand to ensure validity. The data were compiled and processed by the SPSS software, version 17.0. Statistical analysis involved a $95 \%$ confidence interval. During analysis, when the assessed data revealed a non-normal distribution, nonparametric tests were used.

\section{RESULTS}

A total of 1,055 questionnaires/examinations were collected, corresponding to 779 women $(73.7 \%)$ and 276 men (26.3\%). Age distribution by strata is shown on Table 1.

Acne was observed in $61.5 \%(n=648)$ of patients. About $63.2 \%$ of all women had some grade of acne, while $56.8 \%$ of men showed some form of the disease. To ensure a greater level of reading-ease, prevalence by age and sex is shown in Table 1. These values require some insightful reflection and discussion which will be held below. Patient distribution by acne grade is shown in Table 2 .

No significant differences in acne prevalence were found between men (56.8\%) and women (63.2\%) ( $p>0.05$; OR $\left.=0.752[0.561-1.001] ; \chi^{2}=2.443\right)$. No differences were found between genders regarding acne severity (grade) ( $p$ $=0.236$; Kruskal-Wallis $\chi^{2}=5.545$ ).

Only $36.8 \%$ of patients affected by acne were aware of this condition; awareness increased with acne severity: $5 \%$, $19 \%, 49 \%, 90 \%$ and $100 \%$ of patients for grades zero to four, respectively.

Acne onset was reported as follows: $1 \%$ of women reported onset at 1 - 9 years old (y.o.); $93 \%$ of men versus $88 \%$ of women say onset happened from 10 - 19 y.o.; $5 \%$ of men and $8 \%$ of women report acne onset from 20 - 29 y.o.; $2 \%$ of men versus $3 \%$ of women report acne onset from 30 - 39 y.o.. No values were reported in the higher age strata.

The following results were observed regarding consumption of foods usually associated with perceived acne worsening: chocolate $-49 \%$; olives $-41 \%$; fried foods - 29\%; alcohol - 8\%; nuts - $6 \%$.

A statistically significant relationship between fast-food consumption and acne was observed $(p<0.001$; Kendall's

Table 1 - Sample composition and acne prevalence

\begin{tabular}{cccccc}
\hline Age (years old) & $N$ & n affected & Acne prevalence by strata & \multicolumn{2}{c}{ Acne prevalence by gender } \\
\hline $20-29$ & 302 & 233 & $79.9 \%$ & $81.5 \%$ & $75.5 \%$ \\
$30-39$ & 353 & 234 & $64.5 \%$ & $68.2 \%$ & $58.2 \%$ \\
$40-49$ & 277 & 125 & $44.5 \%$ & $45.5 \%$ & $41.5 \%$ \\
$50-60$ & 122 & 58 & $61.5 \%$ & $45.9 \%$ & $46.7 \%$ \\
Total & 1055 & 649 & $63.2 \%$ & $56.8 \%$ \\
\hline
\end{tabular}


Table 2 - Acne prevalence results and their stratification according to the Pillsbury's scale ${ }^{6}$

\begin{tabular}{clc}
\hline Grade & Description & Percentage \\
\hline 1 & Comedones and occasional small cysts confined to the face & $37.5 \%$ \\
2 & Comedones with occasional pustules and small cysts confined to the face & $18.8 \%$ \\
3 & $\begin{array}{l}\text { Many comedones with small and large inflammatory papules and pustules, more extensive but } \\
\text { confined to the face }\end{array}$ & $3.8 \%$ \\
4 & $\begin{array}{l}\text { Many comedones and deep lesions tending to coalesce and canalize, involving the face and the } \\
\text { upper aspects of the torso }\end{array}$ & $0.5 \%$ \\
\hline
\end{tabular}

tau-b $=0.193)$. Analysis of data revealed that subjects who consumed fast-food more than twice monthly were more likely to be affected by acne $(73.8 \%$ vs $58.3 \%)$ and had a two times higher risk of developing this condition $(p<0.001$; $\mathrm{OR}=2.02$ [1.37 - 2.97]; $\left.\chi^{2}=39.960\right)$.

Regarding perceived seasonal changes, $22 \%$ of patients found their acne to worsen in the winter, whereas $12 \%$ believed it improved and $62 \%$ found no changes. A total of $44 \%$ of subjects reported an improvement in the summer, whereas $14 \%$ found this condition worsened and $39 \%$ reported no changes. Only $3 \%$ of patients found acne to worsen in the spring, whereas $17 \%$ found this condition to improve and $62 \%$ found no changes. Finally, $70 \%$ of patients found no changes in the autumn, whereas $8 \%$ found acne to improve and $19 \%$ found it to worsen.

Only $25 \%$ of acne patients reported to have sought some kind of treatment, corresponding to an average monthly cost of $€ 24.98$ and average treatment duration of 3 years. Treatment consisted of facial cream in $71 \%$ of patients, oral medication in $10 \%$, and a combination of facial cream, body cream and tablets in $19 \%$ of patients. Benzoyl peroxide was the main active ingredient, being referred by $14 \%$ of facial cream users.

Subjects were qualitatively inquired about the perceived impact of acne in their lives, in a professional, social and personal set. The results are available in Table 3 .

The prevalence of acne in patients who didn't drink milk or drink skimmed milk is $56.6 \%$, whereas in those who drink semi-skimmed or whole milk is $63.4 \%$. For these values a statistically significant difference was observed: acne was more prevalent in subjects who drink semi-skimmed (reduced-fat) milk or whole milk, compared to subjects who do not drink milk or drink skimmed (fat-free) milk ( $p=0.025$;
$\left.\mathrm{OR}=1.33[1.03-1.70] ; \chi^{2}=5.156\right)$. From the same results, we also found that subjects who drink semi-skimmed or whole milk have a 1.33 times higher risk of acne than those who drink skimmed milk or do not drink milk at all.

Acne was observed in $62.3 \%$ of smokers. A dosedependent relationship between acne severity and the average number of cigarettes smoked everyday was found $(p<0.05$, trend test $=12737,0$; Kendall's tau- $b=0.283 ; p<$ 0.05).

A significant difference in acne prevalence was observed in patients reporting acne in their siblings ( $p<$ $0.001 ;$ OR $=2.63$ [1.73-4.01]; $\chi^{2}=21.601$ ). A relationship was established, regarding acne presence in either parents $\left(p=0.048 ;\right.$ OR $=1.937$ [1.02 - 3.764]; $\left.\chi^{2}=21.601\right)$.

Regarding the prevalence of facial lesions, the following distribution was observed for both, right and left, sides. Respectively, forehead - 45.2 and $42.6 \%$; cheeks - 78.4 and $76.1 \%$; chin and neck - 44.4 and $44.6 \%$.

The number of pustules increased with acne severity; a statistically significant relationship was observed between acne severity and lesion type ( $p<0.001$; Kendall's tau $b=0.344)$. Atrophic scars were present in $18.6 \%$ of acne patients, $19.0 \%$ in women and $16.9 \%$ in men. A positive correlation between scarring and acne grades was found ( $p$ $<0.000$; Kendall's tau $-\mathrm{b}=0.304$ ).

This study also revealed a statistically significant relationship between seborrhea and acne: $79.2 \%$ of subjects with seborrhea also had acne, whereas acne only affected $50.4 \%$ of subjects without seborrhea $(p<0,001$; $\left.\mathrm{OR}=3.8[2.80-5.04] ; \chi^{2}=84.0\right)$. This means that subjects with seborrhea have a 3.8 times higher risk of acne.

Women with alopecia have a 3.5 times higher risk of acne. Acne was observed in $83 \%$ of women with alopecia,

Table 3 - Perceived impact of acne on patients life

\begin{tabular}{ll}
\hline Aspect & Data \\
\hline Professional life & $\cdot 68 \%$ of patients considered acne not to affect their professional lives \\
& $\cdot 24 \%$ reported a small impact \\
& $\cdot 8 \%$ referred considerable interference \\
& $\cdot 60 \%$ of patients found acne to have no impact on their social lives \\
& $\cdot 27 \%$ believed acne to have a small impact \\
& $\cdot 9 \%$ report a considerable effect \\
& $\cdot 50 \%$ of patients referred that acne somewhat affected their personal lives \\
& $\cdot 32 \%$ considered acne to have little impact \\
Personal life & $\cdot 18 \%$ believed that this condition considerably affected their personal lives \\
& $\cdot 8 \%$ of patients affected by grade 3 or 4 acne and aware of their condition reported a certain degree of impact, \\
& on a personal level
\end{tabular}


whereas only $58.5 \%$ of women without alopecia were affected by this condition $\left(p<0.001 ;\right.$ OR $=3.5[2.6-5.0] ; \chi^{2}$ $=23.25)$. Regarding hirsutism, $78.4 \%$ of women affected by this condition also had acne, compared to $49.9 \%$ of women not affected by hirsutism $\left(p<0,001 ; \mathrm{OR}=3.6\right.$ [2.4-4.8]; $\chi^{2}=$ $65.22)$. Women with hirsutism have a 3.6 times higher risk of having acne.

Regarding women taking the contraceptive pill ( $\mathrm{n}=$ 365), no statistically significant relationship was observed between pill type and acne prevalence $\left(p=0.245 ; \chi^{2}\right.$ $=0.76$ ). Also, no difference was shown between oral contraceptives and other hormonal type-contraceptives, such as transdermal patches, subdermal contraceptive implant or contraceptive vaginal rings ( $p>0.05$; KruskalWallis; $\chi^{2}=0.954$ ). No difference was found between nonoral hormonal contraceptives $\left(p>0.05\right.$; Kruskal-Wallis; $\chi^{2}=$ 1.784).

A significant relationship was observed between acne severity (grade) and perceived worsening of lesions during the menstrual period ( $p<0.001$; Kendall's tau $-\mathrm{b}=0.219$ ).

\section{DISCUSSION}

\section{Acne prevalence}

Acne prevalence $(61.5 \%)$ was relatively high compared to the values observed in other studies. ${ }^{2}$ Some of these discrepancies may, to some point, be explained by the chosen sampling method: a convenience sample. Further considerations will be held bellow. Although higher acne frequencies in women are reported, no statistical differences in acne prevalence were found between men $(56.8 \%)$ and women $(63.2 \%)$ in this study. Only $36.8 \%$ of patients affected by acne were aware of this condition, with awareness increasing with severity (grade). Such finding goes according to our prevalence report. ${ }^{2}$ As we mentioned, our prevalence values seem higher than those previously reported. ${ }^{2}$ In fact, careful statistical analysis and an attentive eye show that the values we obtained are very close to those in the mentioned study. Such study was based on self-report, by patients who were randomly present in a university campus and by patients in the waiting areas on the campus's medical center clinics.

The absence of medically trained personnel to confirm findings may mean that some lesions/features found in acne may have been under-reported, leaving milder acne grades unnoticed. When we compared our apparently 'inflated' prevalence values, while leaving only acne graded I patients out of calculus, we both confirmed and added information to the original Collier et $\mathrm{al}^{2}$ study: milder acne grades or symptoms may be socially undervalued, neglected, or even accepted without triggering any reference to acne, which results in an artificially lower acne prevalence. In our study, only $5 \%$ of the 1,055 individuals were aware of having grade I acne, that was present in $37.5 \%(n=396)$ of patients.

Taking such variation into account, our values become very close to those by Collier et $a^{2}$ from 20 - 29 y.o., the prevalence is $43.8 \%$ for men versus $40.0 \%$ for women; from $30-39$ y.o., the prevalence is $16.5 \%$ in men versus
$26.2 \%$ in women; from 40 - 49 y.o., the prevalence is $7.7 \%$ in men versus $16.4 \%$ in women; and from 50 - 60 y.o., the prevalence is $16.7 \%$ in men versus $4.7 \%$ in women. The direct evaluation by properly trained observers appears to expose previously unnoticed grade I acne patients. Our prevalence values show consistent diminishing such as those in the study previously mentioned. Though not tested in this study, the high prevalence in men from 50 60 y.o. may be explained by an increasing prevalence of benign prostate hyperplasia, which can be co relatable to increased dihydrotestosterone levels, ${ }^{7}$ known to contribute to acne pathophysiology. We can only postulate whether women may have had their real prevalence masked by hormonal contraceptive birth control methods or hormonal replacement therapy. ${ }^{2,8-11}$

\section{Diet and tobacco use}

No prior studies evidence a direct relationship between isolated foods and acne onset/worsening. However, a hypercaloric diet appears to have considerable influence on this condition. ${ }^{12}$ The results of this study appear to support this theory, since a relationship between fast-food consumption (nutritional behaviour indicator) and acne was found. According to previous studies, diet influences sebum composition and secretion frequency. ${ }^{12,13}$ One study reported an average of $40 \%$ decrease in sebum secretion and changes to the lipid composition of the skin following prolonged low-calorie diets. ${ }^{14} \mathrm{~A}$ study conducted using labelled exogenous fatty acids, revealed that a small percentage of these acids is taken up as linoleic acid, which undergoes beta-oxidation. ${ }^{12,15}$ This type of oxidation is related to sebaceous gland function and differentiation. ${ }^{12,15}$ Therefore, sebaceous glands effectively use fatty acids from the bloodstream to produce sebum. ${ }^{12,15}$ Meanwhile, a review of several articles mentions that such relation may not exist. ${ }^{16}$

A recent study reports that chocolate and sweets are associated with acne, but failed to investigate the respective roles of sugar, lipids and milk. ${ }^{17}$

Previous works support that milk may induce acne, since it contains 5-alpha-pregnanedione and 5-alpha-androstenedione, which are converted into dihydrotestosterone (DHT) (the primary acne-producing hormone in humans) by enzymes found in pilosebaceous units. ${ }^{18}$ Additionally, insulin-like growth factor (IGF-1) levels in adolescents and young adults are similar to those found in adults with acne. Milk also contains IGF-1, thus increasing endogenous IGF-1 levels. ${ }^{19,20}$ A previous study found a relationship between increased consumption of skimmed (fat-free) or low-fat milk and increased acne severity in adolescent boys (9 - 15 y.o.). ${ }^{21}$ This may be explained by the increased plasma IGF-1 levels found in these subjects. ${ }^{22}$

The recently discovered nuclear transcription factor FoxO1, seems to be a key mediator in acne pathophysiology. ${ }^{23,24}$ Elevated growth factors during puberty and persistent growth factor signals like IGF-1 and insulin (like those due to a Western lifestyle), stimulate 
the export of FoxO1 out of the nucleus into the cytoplasm via activation of the phosphoinositide-3-kinase (PI3K)/Akt pathway. ${ }^{23,24}$ The genes and nuclear receptors involved in acne pathogenesis are disinhibited, leading to increased androgen receptor-mediated signal transduction, increased cell proliferation of androgen-dependent cells, induction of sebaceous lipogenesis and upregulation of Toll-likereceptor-2-dependent inflammatory cytokines, leading to known acne physical features..$^{20,23,24}$

In the present study, a non-significant increase in acne prevalence was observed in subjects who drink the discussed types of milk, compared to those who do not drink milk at all; a statistically significant increase in the risk of developing acne was observed in subjects who drink semi-skimmed (reduced-fat) or whole milk, compared to subjects who do not drink milk or drink skimmed (fat-free) milk. This relationship is possibly explained by the fact that the mentioned hormones are predominantly found in the fat fraction of milk..$^{20,25}$ Nevertheless, a recent study linked milk consumption and acne: milk and whey protein-based products contribute to elevations of postprandial insulin and basal insulin-like growth factor-I (IGF-I) plasma levels, which in turn leads to the already mentioned FoxO1 shift from the cell nucleus into the cytoplasm. ${ }^{19,26}$

The total percentage of smokers in Portugal in 2010 was $25.5 \%{ }^{27}$; in this study, smokers accounted for $29.1 \%$ of participants. Acne prevalence was reported to be significantly higher in active smokers $(40.8 \%$ versus $62.3 \%$ in this study), compared to non-smokers $(25.2 \%$ versus $37.7 \%$ in the present work). ${ }^{28}$ In our study, the analysis also revealed a dose-dependent relationship between acne severity and the average number of cigarettes smoked per day. Other authors also found a significant linear relationship between acne prevalence and the average number of cigarettes smoked per day. ${ }^{29}$ Such relationship to tobacco has been widely studied, with most studies confirming an association, including physiological pathways. ${ }^{28-30}$ Meanwhile, some studies fail to show or reveal a protective effect of smoking: a recent study found tobacco-smoking was protective against acne, but confirmed an association between cannabis-smoking and acne in both adolescent and young adults. ${ }^{17}$ An older study claims that nicotine possibly plays an anti-inflammatory action on acne, being protective against it. ${ }^{31}$

In addition to the role played by genetics in acne incidence, environmental exposure may also constitute a relevant factor. In one study, authors attribute $19 \%$ of acne cases to genetic factors ${ }^{22}$ and therefore genetic factors may also explain particular acne manifestations. ${ }^{22,25}$ This study also found a relationship between acne prevalence and its presence in siblings and, in at least one of the parents, following the line of previous works, which affirm that genetics play a significant role in the onset of acne. ${ }^{32}$

\section{Comorbidities and other known acne features}

The prevalence of facial lesions is higher on the cheeks, differing of that in the younger form of disease. ${ }^{5}$ The found scarring percentage is similar to that found in the same paper (18.6\%). In our work, scarring was correlated to acne grading. Acne scarring is known to be correlated to acne duration. ${ }^{33}$

As previous studies showed, we confirmed a higher risk of acne in women with alopecia. Alopecia is related to high levels of androgens in hair follicles, both in women and men. ${ }^{34}$ Androgen receptors are also found in sebaceous glands; when activated, these receptors stimulate hypersecretion of sebum. ${ }^{34}$

In this study, $78.4 \%$ of women with hirsutism were also affected by acne, compared to only $49.9 \%$ of women without hirsutism. Women with hirsutism have a 3.6 times higher risk of developing acne, confirming previous results of a study conducted by two of the authors of this study. ${ }^{1}$ Hirsutism is caused by high levels of androgens, which are also associated with the onset of acne. ${ }^{35}$ Another report concluded that hirsutism is not related to total testosterone levels, but to high levels of androstenedione and/or dehydroepiandrosterone sulphate (DHEAS). ${ }^{35}$ The authors of the abovementioned report observed that $44.3 \%$ of women with acne also suffered from hirsutism and exhibited high androgen levels. In addition, the authors found that $22.4 \%$ of women with normal androgen levels were affected by acne and alopecia. ${ }^{5}$ In different a study, only $21 \%$ of women with acne also suffered from hirsutism, which is lower than the percentage we found..$^{5}$ It is also important to note that seborrhea, acne, androgenic-type alopecia and hirsutism are present in both polycystic ovary syndrome and late-form congenital adrenal hyperplasia, due to elevated levels of androgens. ${ }^{36}$ In polycystic ovary syndrome, the high levels of luteinizing hormone and hyperinsulinemia work synergistically causing, among other changes, androgen production ${ }^{36}$; in late-form congenital adrenal hyperplasia, a very low level of plasma cortisol (due to 21-hydroxylase deficiency) fails to inhibit the hypothalamic-pituitary-adrenal feedback system, leading to oversecretion of $\mathrm{ACTH}$, resulting in overstimulation of the adrenals, their hyperplasia and increased androgen production. ${ }^{15}$ Late-form congenital adrenal hyperplasia is also characterized by some level of insulin resistance, which results in compensatory hyperinsulinemia which, in turn, may increase the responsiveness of the pilosebaceous unit to androgens. ${ }^{15}$ Our study shows a higher association between feminine acne and hirsutism than other reports, which could be explained by a higher 21-hydroxylase deficiency, that may lead to a late-form congenital adrenal hyperplasia (which can sometimes be clinically presented as a polycystic ovary syndrome), more common in Southern European countries. ${ }^{37}$ This insulin resistance, added to a diet with high caloric ingestion, i.e. mainly composed by high glycemic index carbohydrates and saturated fats, may lead to obesity and should lead one to preemptively invest in a hormonal study. ${ }^{24}$ The discovery of any of these diseases will change treatment, correcting not only dermatological and endocrinal problems, but also solving psychological problems, like self-image and self-esteem issues. Several 
authors advocate that acne may be a risk indicator for increased body mass index and insulin resistance due to exaggerated $\mathrm{mTORC} 1$ signaling by Western diet, explaining the association of acne with increased body mass index, insulin resistance and early onset of menarche. ${ }^{24,38}$

There is indeed a relationship between the use of oral contraceptives and the risk of developing acne. ${ }^{8}$ The reason why this relationship was not found in this study may be related to the fact that data analysis was based on the examinations performed when study questionnaires were filled. Scientific evidence has demonstrated the efficacy of oral contraceptives in the treatment of acne. ${ }^{8-}$ 10 This effect was not evidenced in this study; however, the effects of oral contraceptives may have been masked (by the type of contraceptives used, collected data and sample characteristics). It is important to mention however that previous studies show that progestin-only oral contraceptives, ${ }^{39,40}$ single-rod containing etonogestre ${ }^{41}$ and levonorgestrel-releasing intrauterine systems ${ }^{42}$ may worsen acne symptoms.

The occurrence of lesions during the premenstrual period in $63 \%$ of women with history of acne (compared to $31 \%$ in this study), as well as a $25 \%$ increase in awareness regarding the total number of lesions, are also documented. ${ }^{43}$ These same authors also refer that acne normally worsens 10 days before the menstrual period and that such worsening persists throughout the menstrual period. ${ }^{43}$ These findings are in agreement with the results observed in this study. The referred authors also concluded that acne is linked to the hormonal changes associated with the menstrual cycle.

We failed to find any eventual connection between acne prevalence and specific classes of pharmacological/ medicinal products, which goes against several previous reports, possibly due to small sample size. Such studies refer acne worsening with isoniazid, ${ }^{44}$ corticosteroids, iodides, bromides, lithium, ${ }^{45,46}$ epidermal growth factor receptor inhibitors, cyclosporine, anticonvulsants, antipsychotics, antidepressants, tumor necrosis factor-alpha (TNFalpha) inhibitors, anabolic steroids, danazol, quinidine, azathioprine, cyclophosphamide and testosterone. ${ }^{47,48}$

Although acne is reported to affect personal, social and professional life, this impact was not considered significant by over $30 \%$ of acne sufferers.

\section{Limitations of this study}

This study primarily reflects the Greater Porto area and therefore it is possible that certain values may differ from those of other populations or geographical areas. It is also important to mention that the use of a convenience sample may have artificially biased acne prevalence, as people with other health issues may offer a less-than-ideal representation, and healthy people may, to some point, not use the healthcare facilities and be under-represented. Regarding the dietary issues discussed, it should be noted that no quantification was made, which may have also altered our assessments. Weighting the subjects could also have added some interesting data and solidified known information on the subject of correlation between obesity and acne.

\section{CONCLUSION}

Despite the high prevalence of acne in adults, a large number of acne sufferers either feel unaffected by this condition or are unaware of its existence, particularly in those suffering from less severe forms.

This study evaluated both the presence and awareness of acne, as reported by patients and confirmed by clinical examination.

Many participants believe that acne affects their lives, especially on a personal level. Patients suffering from more severe forms of acne (higher grades) may benefit from the support provided by their general practice doctor and/or specific counseling.

It was not possible to find any connection between acne prevalence and specific classes of pharmacological/ medicinal products, though they are well described.

The results of this study have confirmed that acne prevalence increases with augmented calorie intake, smoking, hirsutism and seborrhoea, stressing the importance of prevention and of primary healthcare awareness and intervention.

\section{ACKNOWLEDGMENTS}

We are grateful for the support of health centers and all of their staff and patients.

\section{PROTECTION OF HUMANS AND ANIMALS}

The authors declare that the procedures were followed according to the regulations established by the Clinical Research and Ethics Committee and to the Helsinki Declaration of the World Medical Association.

\section{DATA CONFIDENTIALITY}

The authors declare that they followed the protocols in use at their working center regarding patient's data publication.

\section{CONFLICTS OF INTEREST}

The authors declare that there are no conflicts of interest.

\section{FUNDING SOURCES}

No subsidies or grants contributed to this work.

\section{REFERENCES}

1. Amado JM, Matos ME, Abreu AM, Loureiro L, Oliveira J, Verde A, et al. The prevalence of acne in the north of Portugal. J Eur Acad Dermatol Venereol. 2006;20:1287-95.
2. Collier CN, Harper JC, Cafardi JA, Cantrell WC, Wang W, Foster KW, et al. The prevalence of acne in adults 20 years and older. J Am Acad Dermatol. 2008;58:56-9. Erratum in: J Am Acad Dermatol. 2008;58:874. 
Cafardi, Jennifer A [added].

3. Gonçalves G, Amado JM, Matos ME, Massa A. The prevalence of acne among a group of Portuguese medical students. J Eur Acad Dermatol Venereol. 2012;26:514-7.

4. Tan JK, Bhate K. A global perspective on the epidemiology of acne. Br J Dermatol. 2015;172:3-12.

5. Goulden V, Stables GI, Cunliffe WJ. Prevalence of facial acne in adults. J Am Acad Dermatol. 1999;41:577-80.

6. Pillsbury DM SWKA. Dermatology Saunders, editor. Philadelphia; 1956.

7. Carson C 3rd, Rittmaster R. The role of dihydrotestosterone in benign prostatic hyperplasia. Urology. 2003;61:2-7.

8. Habif T. Clinical dermatology. $5^{\text {th }}$ ed. Amsterdam: Elsevier; 2010.

9. Bettoli V, Zauli S, Virgili A. Is hormonal treatment still an option in acne today? Br J Dermatol. 2015;172:37-46.

10. Brynhildsen J. Combined hormonal contraceptives: prescribing patterns, compliance, and benefits versus risks. Ther Adv Drug Saf. 2014;5:20113.

11. Vexiau $P$, Chivot $M$. Feminine acne: dermatologic disease or endocrine disease? Gynecol Obstet Fertil. 2002;30:11-21.

12. Wolf R, Matz H, Orion E. Acne and diet. Clin Dermatol. 2004;22:387-93.

13. Katta R, Desai SP. Diet and dermatology: the role of dietary intervention in skin disease. J Clin Aesthet Dermatol. 2014;7:46-51.

14. Pochi PE, Shalita AR, Strauss JS, Webster SB, Cunliffe WJ, Katz HI, et al. Report of the Consensus Conference on Acne Classification, Washington, D.C., March 24 and 25 1990. J Am Acad Dermatol. 1991;24:495-500.

15. Dessinioti $C$, Katsambas A. Congenital adrenal hyperplasia. Dermatoendocrinology. 2009;1:87-91.

16. Davidovici BB, Wolf $R$. The role of diet in acne: facts and controversies. Clin Dermatol. 2010;28:12-6.

17. Wolkenstein P, Misery L, Amici JM, Maghia R, Branchoux S, Cazeau C, et al. Smoking and dietary factors associated with moderate-to-severe acne in French adolescents and young adults: results of a survey using a representative sample. Dermatology. 2015;230:34-9.

18. Makrantonaki E, Ganceviciene R, Zouboulis C. An update on the role of the sebaceous gland in the pathogenesis of acne. Dermatoendocrinol. 2011;3:41-9.

19. Danby FW. Acne and milk, the diet myth, and beyond. J Am Acad Dermatol. 2005;52:360-2.

20. Danby FW. Acne: diet and acnegenesis. Ind Dermatol Online J. 2011;2:2-5.

21. Adebamowo CA, Spiegelman D, Berkey CS, Danby FW, Rockett HH, Colditz GA, et al. Milk consumption and acne in teenaged boys. J Am Acad Dermatol. 2008;58:787-93.

22. Bataille V, Snieder H, MacGregor AJ, Sasieni P, Spector TD. The Influence of genetics and environmental factors in the pathogenesis of acne: a twin study of acne in women. J Invest Dermatol. 2002;119:131722.

23. Melnik BC. FoxO1 - the key for the pathogenesis and therapy of acne? J Dtsch Dermatol Ges. 2010;8:105-14.

24. Seleit I, Bakry OA, Abdou AG, Hashim A. Body mass index, selected dietary factors, and acne severity: are they related to in situ expression of insulin-like growth factor-1? Anal Quant Cytopathol Histpathol. 2014;36:267-78.

25. Spencer EH, Ferdowsian HR, Barnard ND. Diet and acne: a review of the evidence. Int J Dermatol. 2009;48:339-47.

26. Melnik BC. Evidence for acne-promoting effects of milk and other insulinotropic dairy products. Nestle Nutr Workshop Ser Pediatr Program. 2011;67:131-45.

27. Instituto Nacional de Saúde Dr. Ricardo Jorge. Infotabac Relatório Primeira avaliação do impacto da aplicação da Lei do Tabaco. Lisboa: Direcção-Geral da Saúde; 2011.

28. Schäfer T, Nienhaus A, Vieluf D, Berger J, Ring J. Epidemiology of acne in the general population: the risk of smoking. $\mathrm{Br} \mathrm{J}$ Dermatol. 2001;145:100-4.

29. Capitanio B, Sinagra JL, Ottaviani M, Bordignon V, Amantea A, Picardo M. Dermatoendocrinol. 2009;1:129-35.

30. Yang YS, Lim HK, Hong KK, Shin MK, Lee JW, Lee SW, et al. Cigarette smoke-induced interleukin-1 alpha may be involved in the pathogenesis of adult acne. Ann Dermatol. 2014;26:11-6.

31. Mills CM, Peters TJ, Finlay AY. Does smoking influence acne? Clin Exp Dermatol. 1993;18:100-1.

32. Ballanger F, Baudry P, N'Guyen JM, Khammari A, Dréno B. Heredity: a prognostic factor for acne. Dermatology. 2006;212:145-9.

33. Layton AM, Henderson CA, Cunliffe WJ. A clinical assessment of acne scarring. Clin Exp Dermatol. 1994;4:303-8.

34. Rosenfield RL, Lucky AW. Acne, hirsutism, and alopecia in adolescent girls. Clinical expressions of androgen excess. Endocrinol Metab Clin North Am. 1993;22:507-32.

35. Karrer-Voegeli S, Rey F, Reymond MJ, Meuwly JY, Gaillard RC, Gomez F. Androgen dependence of hirsutism, acne and alopecia in women: retrospective analysis of 228 patients investigated for hyperandrogenism. Medicine. 2009;88:32-45.

36. Poretsky L, Piper B. Insulin resistance, hypersensitivity of LH, and dual defect hypothesis for the pathogenesis of polycystic ovary syndrome. Obstet Gynecol. 1994;84:613-21.

37. De Groot LJ, Beck-Peccoz P, Chrousos G, Dungan K, Grossman A, Hershman J, et al. 21-hydroxylase deficiency: classical \& nonclassical congenital adrenal hyperplasia. South Dartmouth: MDText.com, Inc; 2000.

38. Melnik BC, John SM, Plewig G. Acne: risk indicator for increased body mass index and insulin resistance. Acta Derm Venereol. 2013;93:644-9.

39. Ebede TL, Arch EL, Berson D. Hormonal treatment of acne in women. $J$ Clin Aesthet Dermatol. 2009;2:16-22.

40. Lam C, Zaenglein AL. Contraceptive use in acne. Clin Dermatol. 2014;32:502-15

41. Funk S, Miller MM, Mishell DR Jr, Archer DF, Poindexter A, Schmidt $J$, et al. Safety and efficacy of Implanon, a single-rod implantable contraceptive containing etonogestrel. Contraception. 2005;71:319-26.

42. Kailasam C, Cahill D. Review of the safety, efficacy and patient acceptability of the levonorgestrel-releasing intrauterine system. Patient Prefer Adherence. 2008;2:293-302.

43. Lucky AW. Quantitative documentation of a premenstrual flare of facial acne in adult women. Arch Dermatol. 2004;140:423-4.

44. Oliwiecki S, Burton JL. Severe acne due to isoniazid. Clin Exp Dermatol. 1988;13:283-4.

45. Scarfi F, Arunachalam M. Lithium acne. CMAJ. 2013;185:1525.

46. Ayer J, Burrows N. Acne: more than skin deep. Postgrad Med J. 2006;82:500-6.

47. Momin SB, Peterson A, Del Rosso JQ. A status report on drug-associated acne and acneiform eruptions. J Drugs Dermatol. 2010;9:627-36.

48. Du-Thanh A, Kluger N, Bensalleh H, Guillot B. Drug-induced acneiform eruption. Am J Clin Dermatol. 2011;12:233-45. 